\title{
Supporting Reflective Practice in Creativity Education
}

\author{
Norio Ishii \\ Aichi Kiwami College of Nursing \\ 5-4-1, Ichinomiya, Aichi, 491-0063 Japan \\ n.ishii.t@aichi-kiwami.ac.jp \\ +81586288110
}

\begin{abstract}
In this study, we design a learning environment to foster participants' creative attitude and evaluate its effectiveness in a university class. Our educational program consists of the following three phases: (1) introduction (studying the basics of Mindstorms used as a tool), (2) creative activities (producing playground equipment using Mindstorms), and (3) self-reflective activities on the creative processes (each group constructing a diagram describing their own creative processes and discussing the processes). We evaluate the effectiveness based on comparisons of pre- and post-tests and the contents of the participants' discussions. In particular, we confirm the following three learning activities: (1) the participants discussed their creative activities from various viewpoints, (2) they also discussed the viewpoints considered to be important for creative activities, and (3) they realized the importance of idea generation, idea embodiment, and collaboration in creative activities.
\end{abstract}

\section{Author Keywords}

Creativity, reflective practice, classroom instruction.

\section{ACM Classification Keywords}

H.1.2. Models and principles: User/Machine systems; K.3.1. Computers and education: Computer uses in education.

\section{INTRODUCTION}

Recently, various educational courses focusing on creativity, hereafter called "creativity education", have been conducted in engineering education [7,9]. In creativity education, students experience creative activities such as fabricating a robot or building a bridge of straws, helping them to acquire both a creative attitude and engineering knowledge. We believe that such creativity education is crucial not only in engineering education but also in general

Permission to make digital or hard copies of all or part of this work for personal or classroom use is granted without fee provided that copies are not made or distributed for profit or commercial advantage and that copies bear this notice and the full citation on the first page. To copy otherwise, or republish, to post on servers or to redistribute to lists, requires prior specific permission and/or a fee.

$C \& C^{\prime} 05$, April 12-15, 2005, London, United Kingdom.

Copyright 2005 ACM 1-59593-025-6/05/0004 ..\$5.00.

\author{
Kazuhisa Miwa \\ Graduate School of Information Science \\ Nagoya University \\ Furo-cho, Chikusa-ku, Nagoya, 464-8601 Japan \\ miwa@cog.human.nagoya-u.ac.jp \\ +81527894747
}

education. In this study, we designed a learning environment to foster participants' creative attitude in general education and evaluated its effectiveness. In this learning environment, the participants experienced the following two activities.

\section{Activity 1: Experience of Complex Creative Activities}

The first activity involves the participants experiencing complex creative activities such as producing a creative object that can move. We employed a tool called "Mindstorms," which is one of the most popular consumer robotics kits produced by LEGO Co., Ltd. The advantages of using Mindstorms are as follows: (1) expertise in engineering is not needed, and (2) the cost of reconstructing the product is relatively low (the participants can freely rebuild their objects as many times as they want). Therefore, using Mindstorms as a tool enables the participants to consider and embody their ideas relatively easily. The participants in our learning environment are challenged to use Mindstorms to produce a creative object that can move.

Activity 2: Reflection on One's Own Creative Process In the field of learning science, the importance of metacognitive activities such as self-reflection, selfexplanation, and self-regulation has been suggested $[3,4,5]$. In fact, empirical studies have confirmed that metacognitive activities promote learning in various domains such as physics education [6] and programming education [2]. Furthermore, in the field of design education, the importance of metacognitive activities such as selfreflection has also been suggested [15], and some practical studies that intended to foster reflective activities in design have been conducted $[1,14]$.

This second activity involves the participants reflecting on and evaluating their own creative processes. The effects of the reflective activities are as follows: (1) reflective thinking encourages participants to realize the characteristics of their own creative processes and (2) the experience of reflection leads the participants to learn the importance of metacognitive activities. To carry out this activity, the participants are given a diagram describing their creative processes as a base for their reflection. They are asked to reflect on their creative processes while adding 


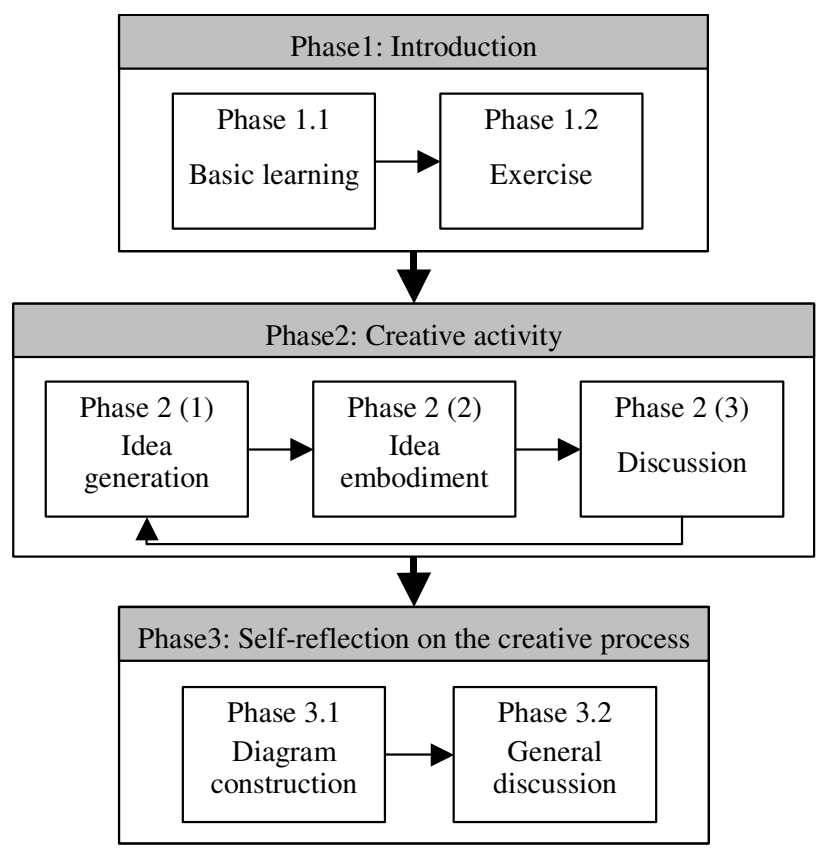

Figure 1. Three phases of the educational program.

detailed information to the diagram, and then they are requested to discuss and evaluate their creative processes.

\section{OVERVIEW OF THE EDUCATIONAL PROGRAM}

Sixteen undergraduate students, not majoring in engineering, participated in our educational program as part of a university class. None of them had any experience using Mindstorms. The participants were divided into five groups, four of which comprised three participants and one of which comprised four participants.

The educational program consisted of three main phases and seven sub-phases (Figure 1) that included seven sessions of class. Each class session lasted for one-and-ahalf hours and was performed at intervals of one week.

\section{Phase 1: Introduction (2 class sessions)}

In Phase 1.1, the participants were given an instructional manual to study the basics of Mindstorms. The participants learned the basics of Mindstorms by using the manual and subsequently constructed a moving car with four wheels by using Mindstorms. In Phase 1.2, the participants freely modified the car constructed in Phase 1.1 for the creative activity exercise in Phase 2.

\section{Phase 2: Creative Activity (4 class sessions)}

In Phase 2, the participants were given the mission to use Mindstorms to produce creative playground equipment that could move by using the following three procedures in each class session. (1) Idea generation (20 minutes). Each participant was required to consider an idea for the playground equipment as a homework assignment, and in this session, the participants discussed their ideas and decided what to produce, recording ideas on the idea sheet. (2) Idea embodiment (60 minutes). The participants tried to embody the playground equipment they had considered. One member of each group was assigned the role of a recorder. The recorder took pictures of his or her own group's process of establishing the product with a digital camera. The job of recorder was rotated every twenty minutes. These activities were performed only in the class. (3) Discussion (10 minutes). In this session, the participants discussed advantages and disadvantages of their creative processes, listing their evaluations on the evaluation sheet.

\section{Phase 3: Self-reflection on the Creative Process (1 class session)}

At the beginning of Phase 3, the participants were given a diagram describing their creative processes as a base for their reflections. The first author drafted all of the diagrams, and Figure 2 shows an example of them.

The diagrams consisted of the following three elements: (a) ideas that they considered in homework (Figure 2 (I)), (b) ideas that they decided to produce in Phase 2 (1) (Figure 2 (II)), and (c) the three most important photographs that the recorder took in Phase 2 (2) (Figure 2 (III)). In Phase 3.1, the participants reflected on their creative processes and added the following two types of information to the diagram: (a) activities to modify their ideas or products (from Figure 2 (1) through Figure 2 (7)), and (b) the links that indicated the transitions of ideas (from Figure 2 (a) through Figure 2 (h)). Figure 3 shows an example situation where the group members are drawing reflective information on the diagram. In Phase 3.2, the participants discussed advantages and disadvantages while referring to the diagram and listed evaluations of their processes on the evaluation sheet.

\section{Pre- and Post-tests}

Before and after the educational program, we conducted pre- and post-tests to evaluate the effectiveness of our program.

\section{EVALUATION OF THE EDUCATIONAL PROGRAM}

First, we introduce each of the finished products that the participants actually constructed. Figure 4 shows photographs of their products and summaries of the playground equipments' movement. All groups were able to embody their ideas and all products could actually move. We then discuss what and how the participants learned through our educational program.

\section{Analysis of Learning Outcome}

We discuss what the participants learned through the experience of creative activities and the reflection on their creative processes.

\section{Analysis of the General Discussion}

First, we discuss what the participants reflected on in terms of their own creative processes by analyzing the contents of 


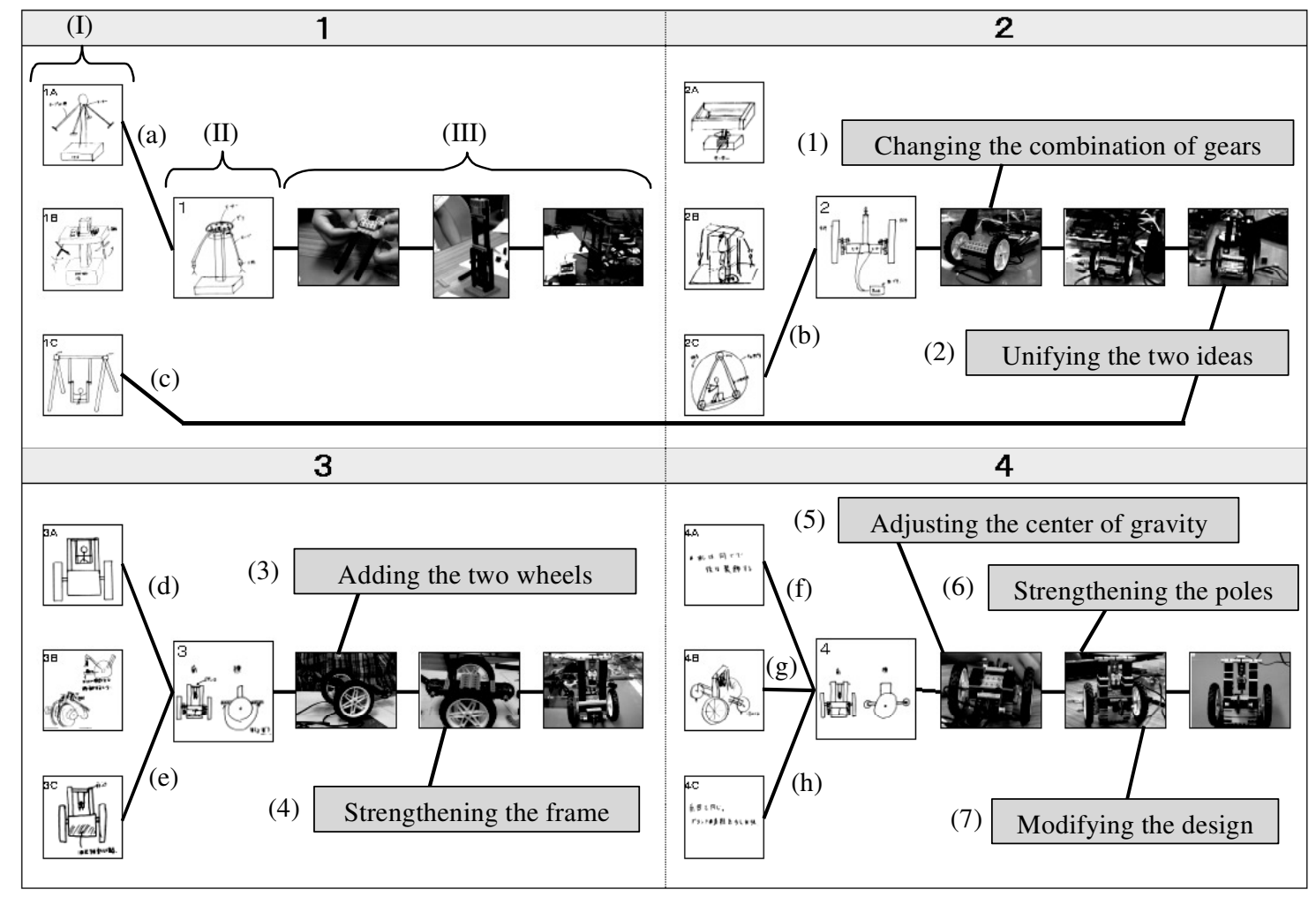

Figure 2. Example of diagram showing creative processes (Group C).

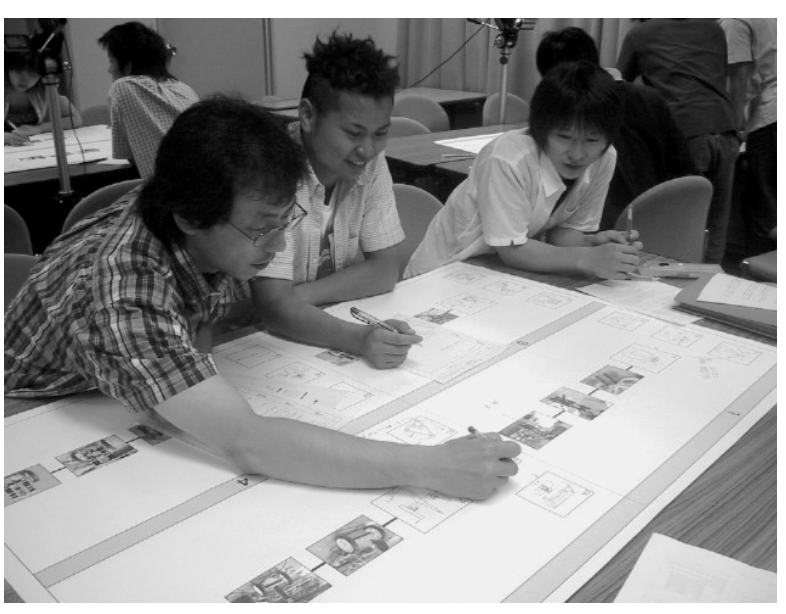

Figure 3. Example situation where the group members are drawing reflective information on the diagram (Group C).

their general discussions in Phase 3.2. Table 1 shows the items of the participants' activities that each group member referred to as advantages or disadvantages, which were also highlighted during the discussions in Phase 3.2. Each item was categorized into one of the following four types: (a) idea generation, such as generating as many ideas as possible, actively modifying ideas, and so on, (b) idea embodiment, including trying to embody ideas in a trial and error manner, analyzing results of the embodiment in detail, and so on, (c) collaboration, such as actively communicating with each other, defining each member's role, and so on, and (d) affective factors, including doing one's best, never giving up, and so on.

Table 2 also shows items that should be considered carefully throughout the activity. For instance, the participants' positive evaluations of their creative processes, such as "we could actively generate ideas," or "we could embody our work while considering the work's appearance," were categorized as advantages. Conversely, their negative evaluations, such as "we could not generate ideas globally," or "we could not focus on the feasibility," were categorized as disadvantages.

Table 1 indicates that the participants mentioned several processes of idea generation, idea embodiment, and collaboration in the discussions in Phase 3.2. Table 2 indicates that they also discussed many points in the creative activities, such as feasibility or the number and types of parts variously. These results indicate that the participants variously reflected on and evaluated both advantages and disadvantages of their creative processes and the viewpoints they considered to be important for creative activities. 


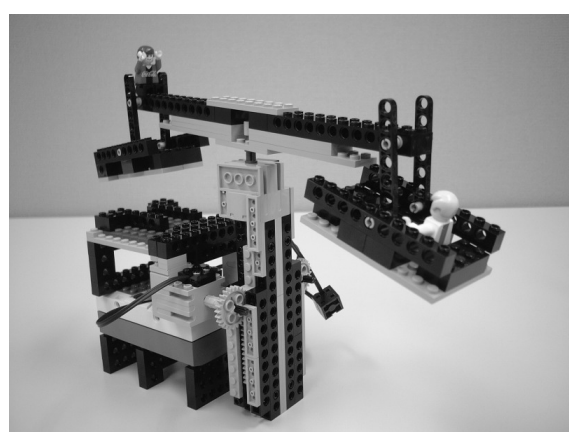

Group A: The playground equipment rotates horizontally and swings up and down.

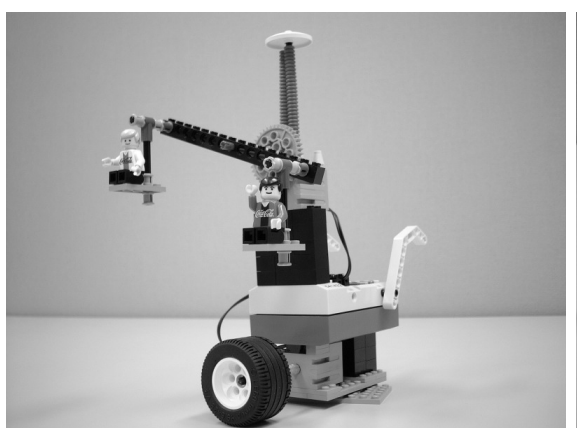

Group B: The playground equipment rotates horizontally and vertically.

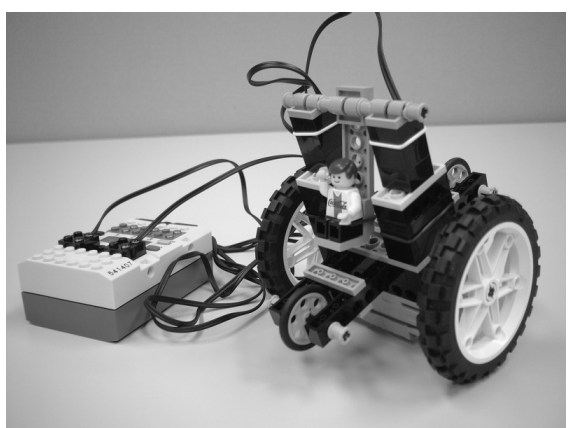

Group C: The playground equipment runs, swinging the seat back and forth.

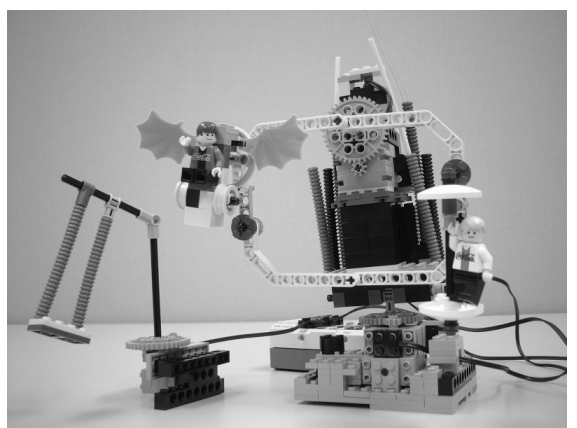

Group D: The playground equipment rotates horizontally and swings from side to side.

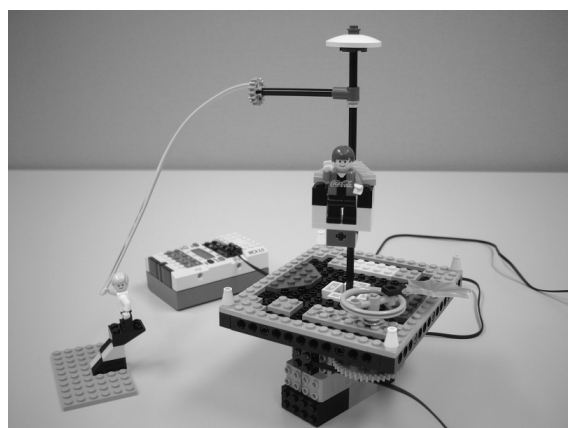

Group E: The playground equipment spins horizontally.

Figure 4. The participants' products and their summaries.

\begin{tabular}{|c|c|c|c|c|c|c|}
\hline & \multirow{2}{*}{$\begin{array}{c}\text { Groul } \\
\text { A }\end{array}$} & Group & \multicolumn{3}{|c|}{ Group Group Group } \\
\hline & & & B & $\mathrm{C}$ & $\mathrm{D}$ & $\mathrm{E}$ \\
\hline \multirow{6}{*}{$\begin{array}{c}\text { Idea } \\
\text { generation }\end{array}$} & Generating ideas actively & & $\mathrm{d}$ & & $\mathrm{d}$ & $\mathrm{d}$ \\
\hline & Generating ideas globally & $\mathrm{d}$ & $\mathrm{d}$ & & & \\
\hline & Considering details of ideas & $\mathrm{d}$ & $\mathrm{d}$ & & $\mathrm{a}$ & $\mathrm{d}$ \\
\hline & Unifying ideas & & & a & & \\
\hline & Changing ideas & $\mathrm{d}$ & & & & \\
\hline & Modifying ideas & & $\mathrm{a}$ & $\mathrm{a}$ & $\mathrm{d}$ & $\mathrm{ad}$ \\
\hline \multirow{2}{*}{$\begin{array}{c}\text { Idea } \\
\text { embodiment }\end{array}$} & $\begin{array}{l}\text { Trying to embody ideas } \\
\text { in a positive way }\end{array}$ & $\mathrm{a}$ & & & & $\mathrm{a}$ \\
\hline & Embodying ideas in many ways & & $\mathrm{a}$ & & $\mathrm{a}$ & \\
\hline \multirow{2}{*}{ Collaboration } & Defining each other's role & & $\mathrm{a}$ & $\overline{\mathrm{ad}}$ & $\mathrm{a}$ & $\mathrm{d}$ \\
\hline & Communicating with each other & a & & & $\mathrm{d}$ & \\
\hline \multirow{2}{*}{$\begin{array}{l}\text { Affective } \\
\text { fact ors }\end{array}$} & Doing one's best & $\bar{a}$ & $\mathrm{a}$ & & & \\
\hline & Working enjoyably & & & & $\mathrm{a}$ & $\mathrm{a}$ \\
\hline
\end{tabular}

Table 1. Categories of participants' activities that were highlighted during the general discussions in Phase 3.2.

\begin{tabular}{|c|c|c|c|c|c|}
\hline & Group & sroup & Sroup & srou & sroup \\
\hline & A & B & $\mathrm{C}$ & D & $\mathrm{E}$ \\
\hline Appearance & & & & $\mathrm{ad}$ & \\
\hline Feasibility & & & d & & d \\
\hline Actuality & & $\mathrm{a}$ & & $\mathrm{a}$ & \\
\hline Complexity & & & d & & \\
\hline Stability & $\mathrm{d}$ & & & $\mathrm{d}$ & \\
\hline Strength & & & & $\mathrm{ad}$ & \\
\hline $\begin{array}{l}\text { Number and } \\
\text { types of parts }\end{array}$ & & & d & d & \\
\hline Time allocation & & $\mathrm{d}$ & & $\mathrm{ad}$ & \\
\hline Consistency & $\mathrm{a}$ & & & & $\mathrm{a}$ \\
\hline
\end{tabular}

Table 2. Categories of important points in creative activities that were highlighted throughout the general discussions in Phase 3.2.

\section{Analysis of Pre- and Post-tests}

Here, we discuss what the participants learned through our educational program by comparing the pre- and post-tests that we carried out before and after the educational program. In these pre- and post-tests, the participants were asked to propose ten activities that they considered to be important in general creative activities. These tests lasted for about fifteen minutes. The participants' answers in each test were categorized into the following six types based on the same criteria used in the analysis of the general discussions: (a) 


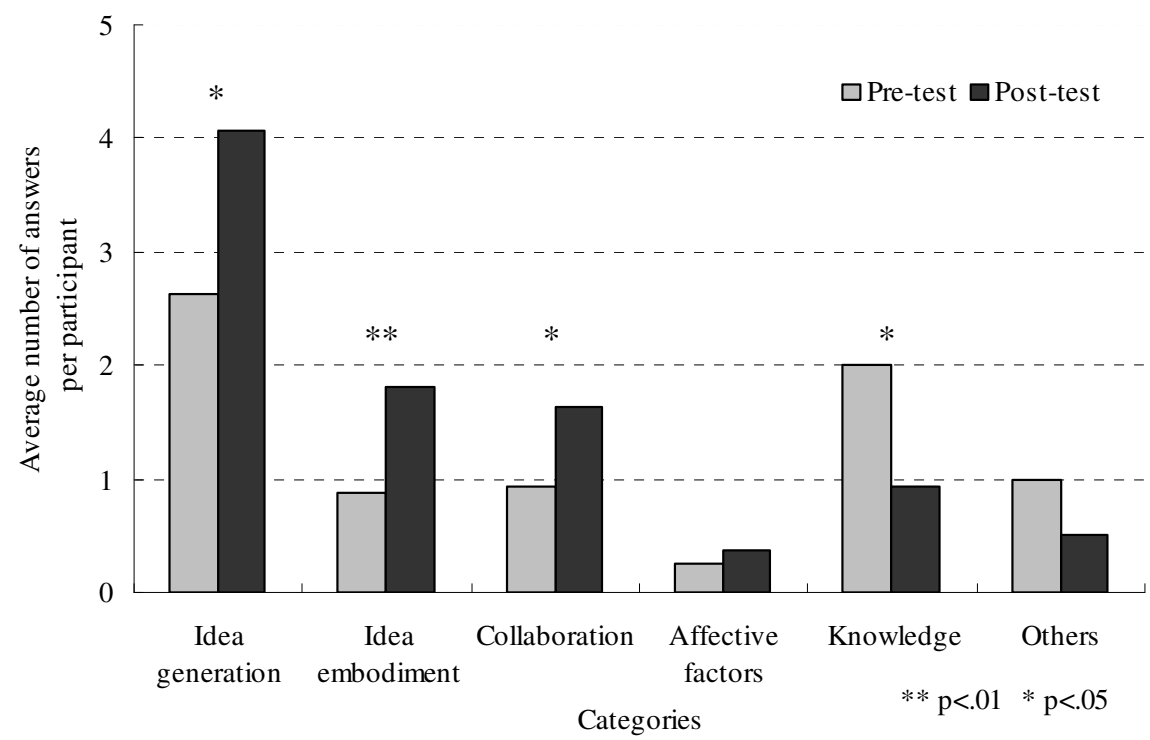

Figure 5. Comparison of the participants' solutions in the pre- and post-tests.

\begin{tabular}{|c|c|c|c|c|c|}
\hline \multirow[t]{2}{*}{ Idea generation } & \multicolumn{5}{|c|}{ Idea embodiment } \\
\hline & Pre & Post & & Pre & Post \\
\hline Considering one's ideas & 56 & 56 & Trying to embody ideas in & 44 & 63 \\
\hline Generating ideas actively & 31 & 44 & a positive way & & \\
\hline $\begin{array}{l}\text { Predicting results of idea } \\
\text { embodiment }\end{array}$ & 31 & 50 & $\begin{array}{l}\text { Getting feedback from results } \\
\text { of idea embodiment }\end{array}$ & 38 & 38 \\
\hline Rethinking previous ideas & 19 & 25 & Embodying ideas in many ways & 0 & 31 \\
\hline Considering details of ideas & 19 & 19 & & & \\
\hline Generating ideas globally & 13 & 6 & & & \\
\hline Unifying ideas & 6 & 50 & & & \\
\hline Modifying ideas & 6 & 31 & & & \\
\hline Changing ideas & 0 & 56 & & & \\
\hline \multirow[t]{2}{*}{ Collaboration } & & & Knowledge & & \\
\hline & Pre & Post & & Pre & Post \\
\hline Communicating with each other & 38 & 38 & Making an observation & 56 & 38 \\
\hline Having a discussion & 31 & 63 & Taking a survey & 50 & 25 \\
\hline Defining each other's role & 6 & 25 & Gathering related information & 31 & 19 \\
\hline
\end{tabular}

Table 3. Contents and proportions of the participants' solutions in the pre- and post- tests.

idea generation, (b) idea embodiment, (c) collaboration, (d) affective factors, (e) knowledge, such as obtaining information from books, observing objects in detail, and so on, and (f) others, such as not doing what others do, thinking like a child, and so on.

Figure 5 shows a comparison of the participants' answers in the pre- and post-tests. As a global tendency, a paired t-test indicated a significant difference in the increase of the number of answered items in the post-test (9.3 per participant) compared to the pre-test (7.7 per participant) $(\mathrm{t}(15)=4.21, \mathrm{p}<.01)$. Moreover, focusing on the categories of the participants' answers, paired t-tests indicated significant differences in the increase of the number of items in idea generation $(\mathrm{t}(15)=2.70, \mathrm{p}<.05)$, idea embodiment $(\mathrm{t}(15)=3.53, \quad \mathrm{p}<.01)$, and collaboration $(t(15)=2.55, \mathrm{p}<.05)$. In contrast, a paired t-test indicated a significant difference in the decrease of the number of knowledge items in the post-test compared to the pre-test $(\mathrm{t}$ $(15)=2.79, \mathrm{p}<.05)$.

Table 3 shows the contents of the four categories above. Table 3 indicates increases in the proportions of items mentioned in the general discussions (see Table 1), such as unifying ideas, changing ideas, and modifying ideas. Additionally, the proportions of items that were not 


\begin{tabular}{lccccccc}
\hline & \multicolumn{7}{c}{ Improvements } \\
& 1 & 2 & 3 & 4 & 5 & 6 & 7 \\
\hline Member A & $\mathrm{m}$ & $\mathrm{c}$ & $\mathrm{c}$ & $\mathrm{m}$ & $\mathrm{m}$ & $\mathrm{c}$ & $\mathrm{m}$ \\
Member B & $\mathrm{I}$ & $\mathrm{c}$ & $\mathrm{c}$ & $\mathrm{c}$ & $\mathrm{c}$ & $\mathrm{m}$ & $\mathrm{m}$ \\
Member C & $\mathrm{m}$ & $\mathrm{c}$ & $\mathrm{c}$ & $\mathrm{m}$ & $\mathrm{m}$ & $\mathrm{m}$ & $\mathrm{m}$ \\
\hline
\end{tabular}

Table 4. Relationship between the improvements listed by each member in the homework assignment and the improvements listed in the construction of the diagram in Phase 3.1 (Group C).

mentioned in the general discussions, such as predicting results of idea embodiment or rethinking previous ideas, also slightly increased. These results indicate that the participants learned heuristics for idea generation, idea embodiment, and collaboration in general creative activities and they realized the importance of them.

Prior studies have suggested the importance of the interaction between the mental and external operations in creative activities [11,12]. The heuristics the participant learned may promote such interaction.

\section{Analysis of Learning Processes}

We confirmed the effectiveness of our educational program through an analysis of the participants' learning outcomes. Next, through an analysis of learning processes, we discussed how the participants learned them.

\section{Characteristics of Reflective Processes}

In our educational program, the participants reflected on their creative processes, which lasted for about six hours. In such a situation, if the participants are given no information on their processes, they may forget their own detailed processes and reflect on incorrect processes. In the educational program, as a homework assignment, each participant was required to reflect on his or her creative processes and list these processes on a sheet. Table 4 shows the relationship between improvements listed by each member of Group $\mathrm{C}$ in the homework assignment and improvements listed in the construction of the diagram in Phase 3.1. Each improvement listed in Table 4 (from improvement \#1 through improvement \#7) corresponds to each of the improvements listed in Figure 2 (from Figure 2 (1) through Figure 2 (7)). These listed improvements were categorized into the following three types: (a) correct identifications, such as improvements on which the participants reflected correctly in the homework assignment, (b) incorrect identifications, such as improvements on which they reflected incorrectly in homework assignment, and (c) missed identifications, such as improvements on which they could not reflect in the homework assignment.

The results indicate that if the participants had been given no information on their processes, they would have forgotten their own detailed processes and reflected on incorrect processes. On this point, we analyzed the participants' processes of reflection in Phase 3.1 and confirmed the following two characteristics of their processes: (1) the participants revised their incorrect identifications (e.g. improvement \#1) by discussing while referring to the diagram and (2) they discussed and shared information on processes on which only some members reflected (e.g. improvement \#1 and from \#4 through \#7). Figure 6 summarizes the reflective activities of Group C about improvement \#1 in Table 4. First, a participant B pointed at the diagram (Figure 6 (I)) and explained that they modified a mechanism at this point (verbalizations \#36). However, this explanation was incorrect. In fact, they modified the mechanism at another point in Figure 6 (II). Next, a participant $A$ required $B$ to provide further explanation (\#37), and B explained it in detail remembering the processes of modification (\#38). Then, A pointed out the mistake by $\mathrm{B}$ on the basis of the information in the diagram (\#41) (Figure 6 (II)). However, B could not accept the indication, and further discussion was continued (from \#42 through \#45). After that, B realized his mistake on his own (\#46), referring to the diagram (Figure 6 (III)). Thus, correct information on improvement \#1 was shared with all group members.

This case suggests that they could realize the characteristics of their creative activities in detail by explaining and evaluating each other's identification of processes. Moreover, it is also suggested that information in the diagram served as a cue for retrieval or as evidence of evaluation.

\section{DISCUSSION}

In this section, on the basis of the results of our educational program, we discuss how we should design and improve a learning environment to foster creative attitudes.

\section{Experience of Complex Creative Activities}

\section{Scaffolding to Support Creative Activities}

Using Mindstorms as a tool enables learners to consider and embody their ideas relatively easily; nevertheless, constructing products using Mindstorms requires learners to have basic mechanical knowledge such as how to construct a mechanism and how to program an algorithm. In such a situation, a teacher has to provide the learners with basic knowledge of Mindstorms and step-by-step exercises before they can engage in creative activities. In our educational program, we provided the participants with scaffolding to experience complex creative activities. Scaffolding is an 


\begin{tabular}{|c|c|c|}
\hline $\begin{array}{r}\text { Protocol } \\
\text { segment }\end{array}$ & Member & Contents \\
\hline 36 & $\mathrm{~B}$ & $\begin{array}{l}\text { We modified a mechanism at this point (he points at (I)). } \\
\text { It was a drastic modification. }\end{array}$ \\
\hline 37 & A & $\begin{array}{l}\text { What did we modify? } \\
\text { Did we modify a program? }\end{array}$ \\
\hline 38 & B & $\begin{array}{l}\text { No. } \\
\text { First, we constructed the playground equipment with a direct- } \\
\text { drive mechanism. } \\
\text { However, the speed of rotation was too fast. } \\
\text { Thus, we then planned a gear-drive mechanism. }\end{array}$ \\
\hline 39 & A & Are you sure about that? \\
\hline 40 & B & There is no doubt about it. \\
\hline 41 & A & $\begin{array}{l}\text { But, this is the gear-drive mechanism (he points at (II)). } \\
\text { Look at this! (he repeatedly points at (II)) } \\
\text { It may be that we did not modify that point at all. }\end{array}$ \\
\hline 42 & $\mathrm{~B}$ & No. \\
\hline 43 & A & Really? \\
\hline 44 & $\mathrm{~B}$ & $\begin{array}{l}\text { You are wrong. } \\
\text { We must have planned the gear-drive mechanism at this point, } \\
\text { since the speed of rotation was too fast (he points at (I)). }\end{array}$ \\
\hline 45 & A & We modified it at this point (he points at (II)) \\
\hline 46 & B & $\begin{array}{l}\text { I realized that we planned the gear-drive mechanism, since the } \\
\text { speed of rotation was too fast at this point (he points at (III)). }\end{array}$ \\
\hline 47 & A & $\begin{array}{l}\text { We needed to control the speed of rotation at this point (he also } \\
\text { points at (III)). }\end{array}$ \\
\hline
\end{tabular}

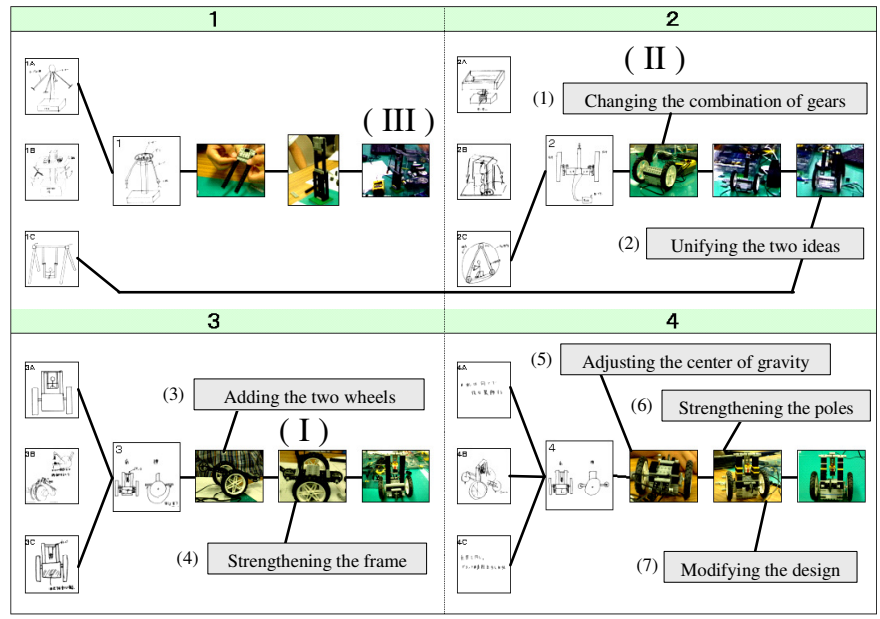

Figure 6. Example of the reflective activities of Group C.

external support that enables a learner to achieve a goal that could not otherwise be reached. In the field of learning science, the importance of scaffolding for learners' activities has been discussed [10,13]. In the educational program, we gave the participants step-by-step goals for their creative activities, such as acquiring basic knowledge of Mindstorms (Phase 1.1), constructing a moving four- wheeled car (Phase 1.1), and modifying that car (Phase 1.2), before they attempted the main task of producing creative playground equipment (Phase 2). In such experience-based creativity education, a teacher should provide the learners with not only a goal but also scaffolding that encourages creative activities. 


\section{Reflection on One's Own Creative Process}

\section{Providing Information on Creative Processes}

We confirmed that the participants explained and evaluated their processes on the basis of the information in the diagram and that they could realize the characteristics of their creative activities more deeply. In contrast, we confirmed that if the participants had been given no information on their processes, they would have forgotten their own detailed processes and reflected on incorrect processes. Hershkowitz and Schwarz [8] confirmed such a phenomenon, referred to as purification, in their educational program in mathematics. In our educational program, we gave the participants a diagram describing their creative processes for their reflective activities in Phase 3. By doing so, they could correctly reflect on their creative processes in detail. However, excessive information may hinder learners' spontaneity. Our study implies that it is important, when having the learners reflect on their own processes, to provide only basic information that serves as a cue for their retrieval and discussion.

\section{Increasing Opportunities for Reflective Activities}

In our study, we expected two kinds of effects of the reflective activities: (1) reflective thinking encourages participants to realize the characteristics of their own creative processes, and (2) the experience of reflection leads the participants to learn the importance of metacognitive activities. As for the first point, the participants actually learned various heuristics for general creative activities and realized the importance of them throughout our educational program. As for the second point, however, none of them realized the importance of the metacognitive activities they experienced, such as reflection and evaluation. One reason for this might be that the participants experienced reflective activities by using a diagram only once. This observation suggests the importance of increasing the opportunities for reflective activities and leading learners to apply their experiences to other creative activities in various domains.

\section{CONCLUSIONS}

In this study, we designed a learning environment to foster participants' creative attitudes and evaluated its effectiveness. This learning environment consisted of two activities: (1) experience of complex creative activities, and (2) reflection on one's own creative process. First, through an analysis of the participants' learning outcomes, we investigated what the participants learned and thus confirmed the effectiveness of our educational program. Second, through an analysis of the participants' learning processes, we investigated how the participants learned them, and the results suggest that it is important, when having the learners reflect on their own processes, to provide basic information that serves as a cue for retrieval or as evidence of evaluation.

\section{REFERENCES}

1. Adams, R.S., Turns, J., and Atman, C.J. Educating effective engineering designers: The role of reflective practice. Design Studies, 24, 3(2003), 275-294.

2. Bielaczyc, K., Pirolli, P.L., and Brown A.L. Training in self-explanation and self-regulation strategies: Investigating the effects of knowledge acquisition activities on problem solving. Cognition and Instruction, 13, 2(1995), 221-252.

3. Bransford, J.D., Brown, A.L., and Cocking, R.R. How People Learn: Brain, Mind, Experience, and School. National Academy Press, Washington, DC, 1999.

4. Brown, A.L. Metacognition, executive control, selfregulation, and other more mysterious mechanisms. In F.E. Weinert and R.H. Kluwe (Eds.), Metacognition, Motivation, and Understanding. Lawrence Erlbaum Associates, Hillsdale, NJ, 1987.

5. Chi, M.T.H., Bassok, M., Lewis, M.W., Reimann, P., and Glaser, R. Self-explanations: How students study and use examples in learning to solve problems. Cognitive Science, 13, 2(1989), 145-182.

6. Chi, M.T.H., de Leeuw, N., Chiu, M., and LaVancher, C. Eliciting self-explanations improves understanding. Cognitive Science, 18, 3(1994), 439-477.

7. Elata, D. and Garaway, I. A creative introduction to mechanical engineering. International Journal of Engineering Education, 18, 5(2002), 566-575.

8. Hershkowitz, R. and Schwarz, B.B. Reflective processes in a mathematics classroom with a rich learning environment. Cognition and Instruction, 17, 1(1999), 65-91.

9. Hirose, S. Creative education at tokyo institute of technology. International Journal of Engineering Education, 17, 6(2001), 512-517.

10.Hmelo, C.E., Holton, D.L., and Kolodner, J.L. Designing to learn about complex systems. The Journal of the Learning Sciences, 9, 3(2000), 247-298.

11. Ishii, N. and Miwa, K. Interactive processes between mental and external operations in creative activity: A comparison of experts' and novices' performance. Proceedings of the Fourth Creativity \& Cognition Conference, ACM Press (2002), 178-185.

12. Gero, J.S. Computational models of creative designing based on situated cognition. Proceedings of the Fourth Creativity \& Cognition Conference, ACM Press (2002), 3-10.

13.Linn, M.C. and Hsi, S. Computers, Teachers, Peers: Science Learning Partners. Lawrence Erlbaum Associates, Mahwah, NJ, 2000.

14. Oxman, R. Educating the designerly thinker. Design Studies, 20, 2(1999), 105-122.

15.Schön, D. Educating the Reflective Practitioner. JosseyBass, San Francisco, CA, 1987 